Final version published in Chemical Engineering and Processing: Process Intensification, 2015, 95, 1-8

\title{
Energy Consumption Estimation in the Scaling-up of Microwave Heating Processes
}

\author{
J.M. Bermúdez ${ }^{\mathrm{a}}$, D. Beneroso ${ }^{\mathrm{b}}$, N. Rey-Raap ${ }^{\mathrm{b}}$, A. Arenillas ${ }^{\mathrm{b}}$, J.A. Menéndez ${ }^{\mathrm{b}}$ * \\ ${ }^{a}$ Chemical Engineering Department, Imperial College London, SW7 2AZ, London, \\ United Kingdom \\ ${ }^{\mathrm{b}}$ Instituto Nacional del Carbón, CSIC, Apartado 73, 33080 Oviedo, Spain \\ * Corresponding author. Tel.: +34 985 118972; Fax: +34 985297672 \\ E-mail address: angelmd@incar.csic.es
}

\begin{abstract}
The specific energy consumption of six different microwave-driven processes and equipments has been studied and it was found that the scale used dramatically affects it. Increasing the amount of sample employed from 5 to $100 \mathrm{~g}$ leads to a reduction in the specific energy consumption of $90-95 \%$. When the amount of sample is $200 \mathrm{~g}$ or higher, the specific energy consumption remains practically constant. This means that to assess the real energy efficiency of a microwave-driven process a minimum mass of about 200 g needs to be used. The energy results can then be easily extrapolated to larger scales. Otherwise, a correlation should be used to avoid overestimated energy values and inaccurate energy efficiencies.
\end{abstract}

\section{Keywords}

Microwave heating, Energy Consumption, Scale-up, Efficiency 


\section{Introduction}

Microwave energy has attracted increasing interest among the scientific community since the late eighties as an alternative method of heating $[1,2]$. A good indicator of this interest is the evolution in the number of scientific publications in the last thirty years (Fig.1). The increase in scientific efforts to develop microwave heating can be attributed to the several advantages that this technology offers over conventional heating technologies. These include: (i) non-contact heating; (ii) rapid heating; (iii) selective heating; (iv) a quick start/stop facility; (v) a high level of safety and automation; and (vi) heating from inside the body of the material (i.e., energy conversion instead of heat transfer) $[1,3]$. All of these advantages have promoted research into the application of microwave heating to a wide range of different processes including waste and biomass valorization [4], material synthesis [5, 6], metallurgy and mineral processing [3, 7], catalysis [8], organic synthesis [9], environmental technology [7, 10], biomass extraction [11], etc.

The viability of all these processes is highly affected by their energy costs $[12,13]$. Lately, several authors have pointed out that the energy efficiency of microwave heating could also represent an important advantage over conventional heating technologies $[10$, $14,15]$. Yet, in spite of the increasing interest in this technology, there is still very little information about its energy efficiency [16]. For example, just a few reports in the field of organic synthesis (homogeneous and heterogeneous catalysis) have assessed the energy efficiency of the microwave in comparisson with conventional heating. In these works, it has been found that a case-by-case analysis is needed, since the conclusions vary depending on the reaction studied $[13,17]$. Besides these works, not much studies 
have been published on this aspect of microwave heating (Fig. 1), and some of these are inconclusive. Factors like equipment design, the radiation frequency (915 or 2450 $\mathrm{MHz}$ ), the mode of heating, the specific power and the scale of the process need to be carefully analyzed before conclusions that might favor or weigh against the use of microwave energy for a specific process can be drawn. A matter of great importance is the scale that is chosen to evaluate the potential of microwave heating. The results of a statistical study on this matter can be seen in Fig. 1. To collect the data, Scopus ${ }^{\circledR}$ was used as source. A search using the keyword "Microwave heating" limited to the fields of Engineering, Chemistry, Material Science, Chemical Engineering, Pharmacology, Toxicology and Pharmaceutics, Energy and Environmental Science was carried out, excluding those works that included words such as "characterization" or "dielectric properties", with the aim of narrowing the search down to those articles focused on applied microwave heating. To construct the pie graph, including the clasification of the works and their proportion by sample weight, in addition to the corresponding percentage of these proportions from which conclusions about energy consumption are drawn, a stratified probabilistic sampling was carried out. The global population of works was divided by the year of publication and $10 \%$ of the works from each year (which approximately account for a total of 1200 articles all randomly chosen) were reviewed. The results of this study show that most of the works published to date have been performed at lab-scale, employing only a few grams of sample (Fig. 1). However, as will be demonstrated in this paper, to draw conclusions about the viability of a process based on results obtained at such a low scale can be risky and, depending on the amounts of sample used in the experiments, sometimes meaningless. Moreover, nowadays most research efforts in this field are focused on the scaling-up of microwave processes and the first encouraging results are appearing [12, 13, 18, 19]. For these 
reasons it is important to determine how the energy consumption of microwave-heated processes varies depending on the scale used. This will make a valuable contribution to assessing its viability at industrial level. The energy utilization efficiency depends on the geometric characteristics of the resonant cavity and the reactor, the design and effectiveness of the impedance matching circuit to minimize the reflected power and the dielectric properties of the bulk. Actually, when changing the dimensions of the reactor, the scattering properties of the system change. Hence, the impedance matching circuit to minimize the reflected power will determine the energy efficiency. Nevertheless, when no hardware is present to reduce the reflected power, there may be regions in the attainable reactor size range, where heat generation and utilization efficiency vary nonmonotonically with varying reactor size [20].

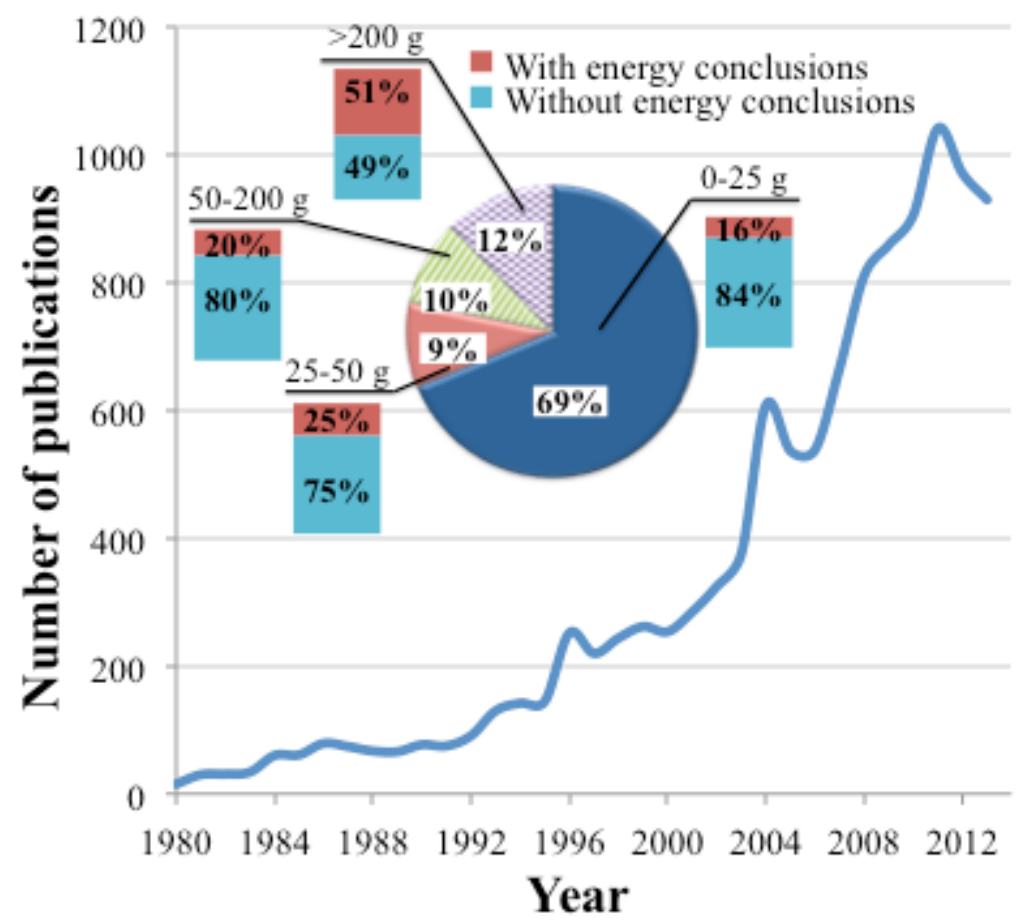

Figure 1. Evolution of the number of scientific publications related to microwave heating. Distribution of these publications in terms of the mass used in the study and the energy conclusions drawn (Source: Scopus $\left.{ }^{\circledR}\right)$. 
The goal of this work is to study the variation of the energy expenditure (taking into account the absorbed energy, reflected energy and even heating losses) of microwave heating as a function of the scale used. For this purpose, an analysis of the energy consumption of six different microwave-assisted processes was conducted in an attempt to find a general trend with the scale that might be extrapolated to other cases. The results obtained will help to assess the viability of microwave-heated processes.

\section{Experimental}

The following processes were studied: the heating of $\mathrm{SiC}$ and the torrefaction of wheat straw (adapted from the literature) [21, 22], the heating of water, the synthesis of xerogels, the high temperature heating of charcoal and the microwave-assisted grinding of metallurgical coke (directly studied in our labs). The experimental methodologies and the equipment used (Fig. 2) for these processes are described below.

Water heating. The heating of water was selected since it resembles the experimental conditions of many systems used in organic chemistry synthesis [16]. The equipment shown in Fig. 2a was used to study the microwave energy consumption of the process. The equipment is composed of a multimode microwave oven with a $700 \mathrm{~W}$ magnetron, using a frequency of $2.45 \mathrm{GHz}$. The dimensions of the equipment are shown in Table 1. The microwave device is also equipped with a thermocouple type $\mathrm{K}$ connected to a PID controller which controls the amount of power delivered and allows the temperature to be monitored and controlled [23]. The amount of energy consumed throughout the process was measured by means of a power meter connected to the microwave device and recorded on DQ-factory software. Different masses of distilled 
water ranging from 5 to $900 \mathrm{~g}$ were heated up to $85^{\circ} \mathrm{C}$ in closed beakers which dimensions were proportional to the amount of water used. Once this temperature was reached, it was maintained for 15 minutes.

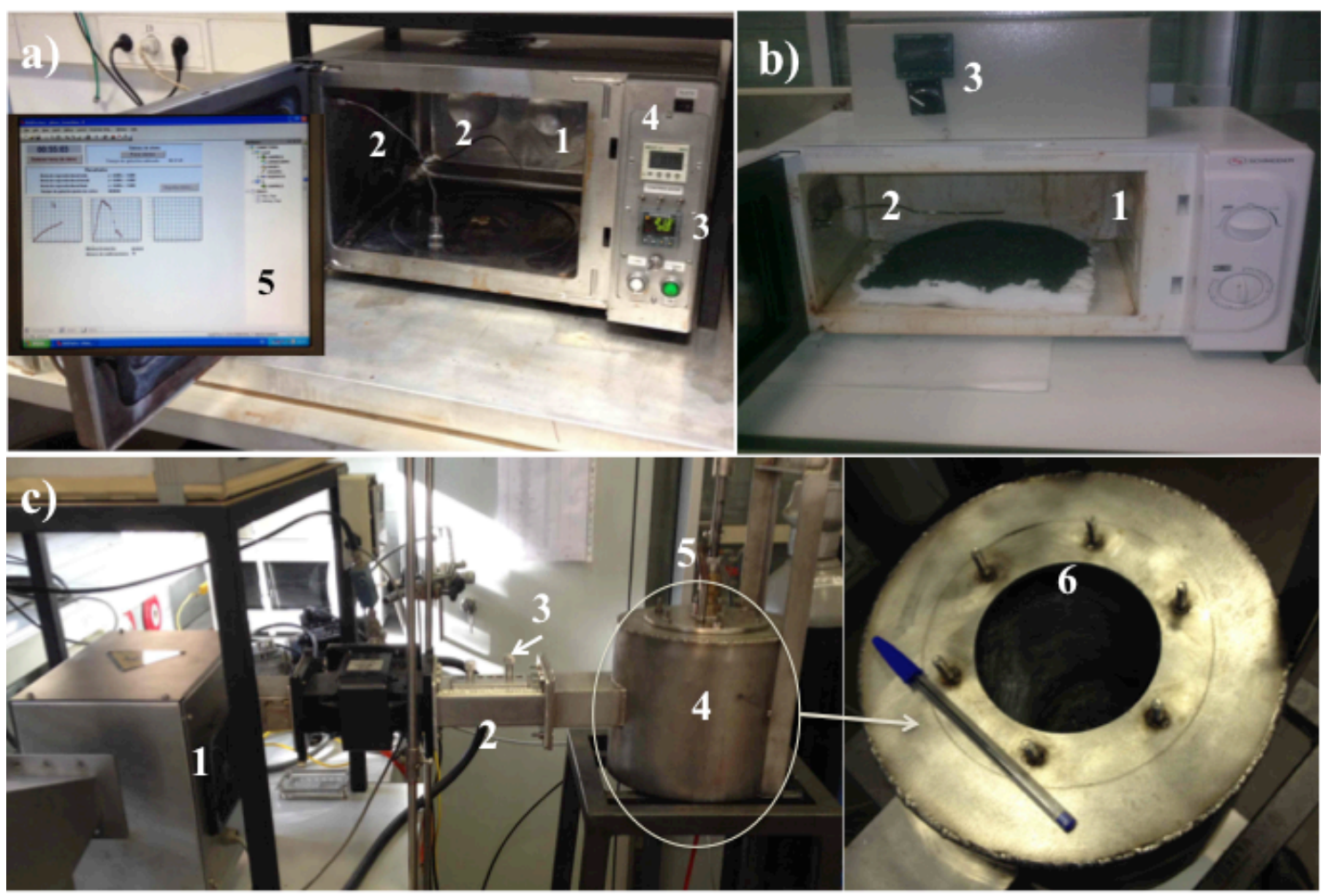

Figure 2. Equipment used in the: (a) water heating and synthesis of xerogels (1.

Microwave cavity; 2. Thermocouples; 3. PID temperature controler; 4. power meter; 5.

Power monitoring software); (b) Coke grinding (1. Microwave cavity; 2.

Thermocouple; 3. Power meter); (c) High temperature heating of charcoal (1.

Magnetron; 2. Waveguide; 3. Tuning screws; 4. Microwave cavity - outside; 5. Stirring shaft; 6. Microwave cavity - inside). 
Table 1. Characteristics of the microwave equipment used in the different processes studied

\begin{tabular}{|l|c|c|c|c|}
\hline \multicolumn{1}{|c|}{ Process } & $\begin{array}{c}\text { Heating } \\
\text { mode }\end{array}$ & Frequency & Power & Dimensions (cm) \\
\hline $\begin{array}{l}\text { Water } \\
\text { heating - } \\
\text { Xerogel } \\
\text { synthesis }\end{array}$ & Multimode & $2.45 \mathrm{GHz}$ & $700 \mathrm{~W}$ & \\
\hline $\begin{array}{l}\text { High } \\
\text { temperature } \\
\text { carbon } \\
\text { heating }\end{array}$ & Unimode & $2.45 \mathrm{GHz}$ & $2000 \mathrm{~W}$ & \\
\hline $\begin{array}{l}\text { Coke } \\
\text { grinding }\end{array}$ & Multimode & $2.45 \mathrm{GHz}$ & $700 \mathrm{~W}$ & \\
\hline
\end{tabular}

Gelation and curing of RF xerogels. The microwave-induced synthesis of Resorcinol/Formaldehyde (RF) xerogels is a simple and fast method for preparing welldeveloped porous materials. These materials are obtained by the polymerization reaction between resorcinol and formaldehyde in the presence of a solvent (Fig. 3). This process involves two main stages: i) addition reaction in which hydroxymethyl derivatives of resorcinol are formed and, ii) condensation reaction in which the hydroxymethyl derivatives are linked by methylene and ether bonds. The microwave 
energy consumption of this process was studied using the same experimental set-up as in the case of the heating of water shown in Fig 2a. Different initial masses of precursor solution ranging from 5 to $3000 \mathrm{~g}$ were prepared according to the experimental method described elsewhere [24]. Briefly, resorcinol (Indspec, 99\%) was first dissolved in deionized water in an unsealed glass beaker under magnetic stirring. After disolution, formaldehyde (Ercros, 37wt. \% in water, stabilized by $10-15 \%$ methanol) was added and the mixture was stirred until a homogeneous solution was obtained. The final $\mathrm{pH}$ value was adjusted by adding sodium hydroxide until a $\mathrm{pH}$ value of 6.5 was attained. All xerogels synthesized were prepared at the same $\mathrm{pH}$ value in order to ensure the same reaction rate and to avoid variations in microwave energy consumption. Each solution was placed in the microwave cavity at $85^{\circ} \mathrm{C}$ for 10000 seconds to undergo the gelation and ageing stages until a stable solid material was obtained. The textural properties of the gels were studied to check if the materials using synthetized different masses of precusors were comparable. The results showed that the textural properties of the different materials were very similar (Table 2). Moreover, the scale-up has been proven by the company Xerolutions, S.L., in a microwave device designed for that purpose. It has been found that well-developed porous materials can be obtained if the microwave device is correctly designed. Furthermore, materials prepared from both microwave devices are comparable and therefore, it has been demonstrated that the process is easily scalable. 

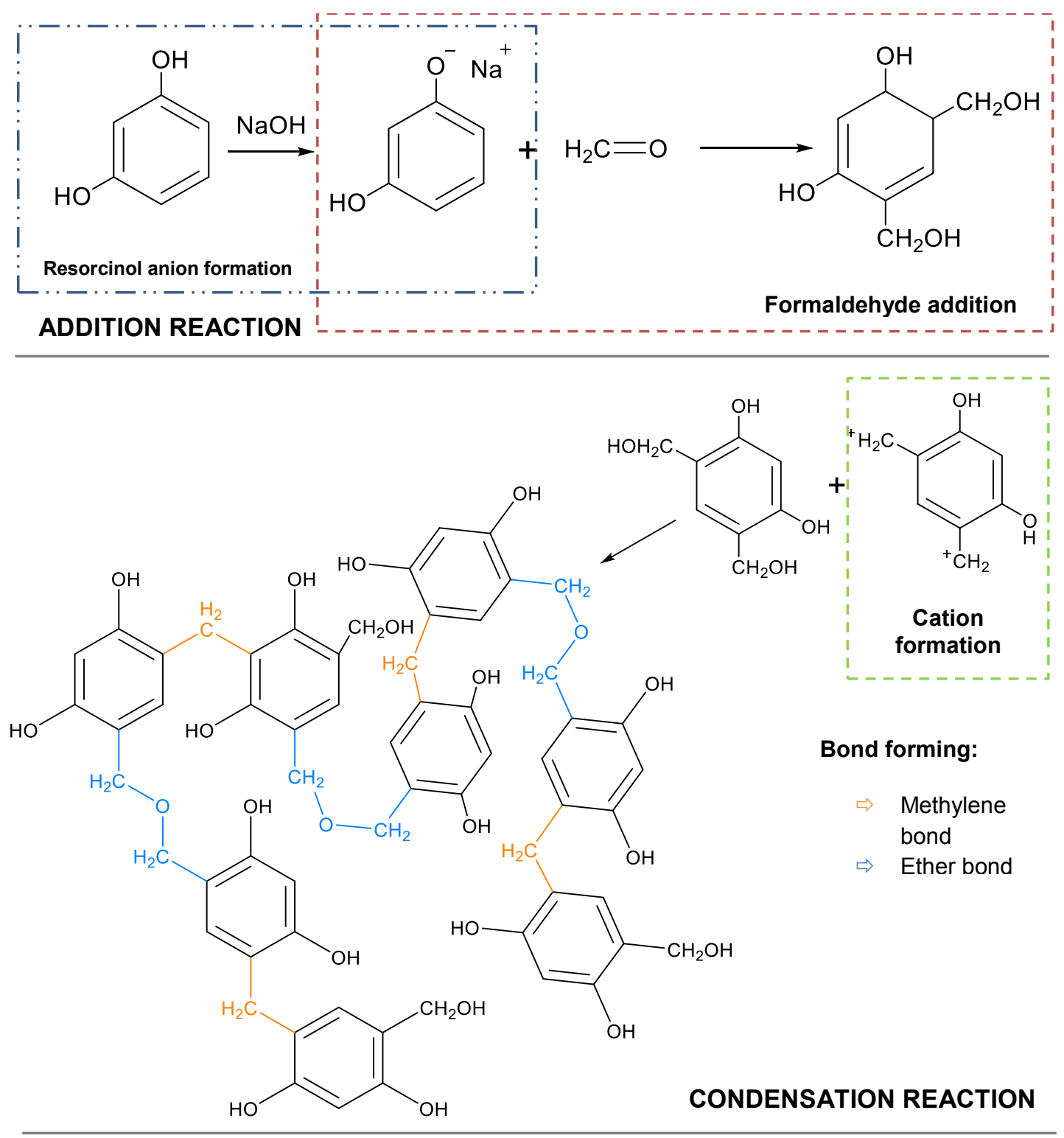

Figure 3. Mechanism of the polymerization reaction between resorcinol and formaldehyde (from [25]).

Table 2. Textural properties of the xerogels synthetized from different initial masses of precursor.

\begin{tabular}{c|ccc}
\hline Precursor mass & $\begin{array}{c}\text { Surface area, } \mathrm{S}_{\mathrm{BET}} \\
\left(\mathrm{m}^{2} / \mathrm{g}\right)\end{array}$ & $\begin{array}{c}\text { Volume of pores } \\
\left(\mathrm{cm}^{3} / \mathrm{g}\right)\end{array}$ & $\begin{array}{c}\text { Pore size } \\
(\mathrm{nm})\end{array}$ \\
\hline $200 \mathrm{~g}$ & 303 & 0.63 & 10 \\
$1000 \mathrm{~g}$ & 353 & 0.70 & 11 \\
$20000 \mathrm{~g}^{\text {(a) }}$ & 494 & 1.05 & 15 \\
\hline
\end{tabular}

(a) Data from the industrial process of Xerolutions, S.L. 
High temperature heating of carbon materials. Certain processes involving carbonaceous materials are performed at high temperatures. These include gasification, reforming reactions, carbonization, pyrolysis or production of activated carbons [26, 27]. The energy consumption of these microwave-driven processes was studied using the equipment shown in Fig. 2c. The equipment is composed of a microwave magnetron operating at $2.45 \mathrm{GHz}$ with a maximum output power of $2 \mathrm{~kW}$ connected to a single mode waveguide. The waveguide directs the microwave energy towards a resonant cavity where the sample is placed. This cavity consists of a ceramic cylinder, which is transparent to microwaves, with an internal diameter of $85 \mathrm{~mm}$, a height of $150 \mathrm{~mm}$ and a thickness of $7.5 \mathrm{~mm}$, in which an overhead stirrer is embedded. Moreover, the cavity is insulated to minimize the heat released to the environment. The reflected power is almost totally avoided by means of stub tuners to prevent magnetron from damage and efficiency reduction. Although the stubs are not able to completely eliminate the reflected energy, they are able to minimize it until several orders of magnitude below emitted power. Moreover, the reflected power was not detected by sensors 2000 times more sensible than the sensors used to measure the emitted power. Therefore, it can be assured that the reflected power was less than $0.05 \%$ of the emitted power and its influence in the energy consumption of the system is negligible. Different amounts of charcoal, ranging from 5 to $200 \mathrm{~g}$, were heated up to $900{ }^{\circ} \mathrm{C}$ and maintained at this temperature under a $\mathrm{N}_{2}$ atmosphere, after having been previously purged with $\mathrm{N}_{2}$ for 10 minutes at a flow rate of $0.2 \mathrm{~L}_{\mathrm{STP}} \mathrm{min}^{-1}$ to ensure an oxygen-free atmosphere, and so characteristic conditions of carbonization or pyrolysis processes. The microwave power consumed to keep the charcoal at $900{ }^{\circ} \mathrm{C}$ during $1 \mathrm{~h}$ was recorded. 


\section{Final version published in Chemical Engineering and Processing: Process Intensification, 2015, 95, 1-8}

Microwave-assisted grinding of metallurgical coke. Certain materials can be ground more easily by subjecting them to short pulses of microwave irradiation before the grinding process. In this case, metallurgical coke was selected as the model material. The experimental procedure has been described elsewhere [28]. In brief, the coke was dried in a stove until completely dry. Then it was sieved into four particle size fractions $(1-2,2-3,3-4$ and $4-5 \mathrm{~mm})$. To prepare homogeneous samples (total mass sample ranging from 5 to $500 \mathrm{~g}$ ), the four particle size fractions were mixed in equal mass percentages $(25 \mathrm{wt} \%)$. The samples were then treated in the equipment shown in Fig. 2b. This device is a multimode oven that operates at a constant power of $700 \mathrm{~W}$ and a frequency of $2.45 \mathrm{GHz}$. The amount of energy consumed in the process for each mass was recorded by means of a watt-hour meter. The samples were subjected to microwave pulses to ensure an improvement in their grindability of $25 \%$. The microwave irradiation was applied using three pulses of 3 seconds duration each. Thus, $3 \mathrm{~s}$ of irradiation were followed by $3 \mathrm{~s}$ without irradiation, accounting for a total irradiation time of 9 seconds for all the samples. The sample was spread in the center of the microwave cavity, as homogeneously as possible, over a circular area ranging from 100 $\mathrm{cm}^{2}$ to $250 \mathrm{~cm}^{2}$, depending on the sample size. The sample was placed on an insulating layer of quartz wool. Then, a Retsch MM400 ball mill was used to grind both the treated and untreated coke samples. To evaluate the improvement in grindability, the portion of particles larger than $1 \mathrm{~mm}$ after 3 min of milling, at a frequency of $10 \mathrm{~Hz}$, was used as the milling grade indicator.

\section{Results and discussion}

Fig. 4 shows the variation in specific energy consumed for each mass of sample in all the processes of this study. 
a)

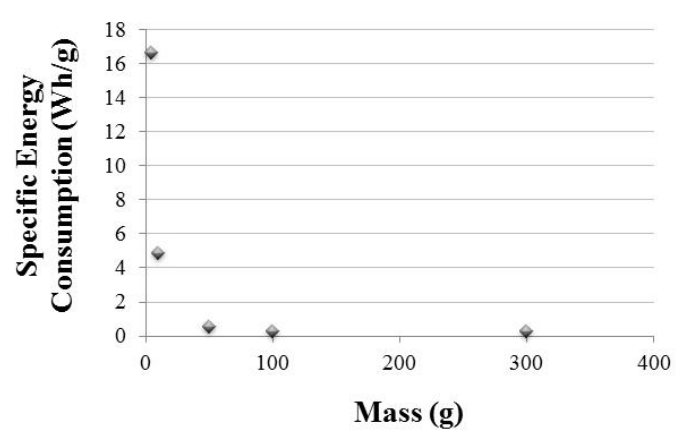

c)

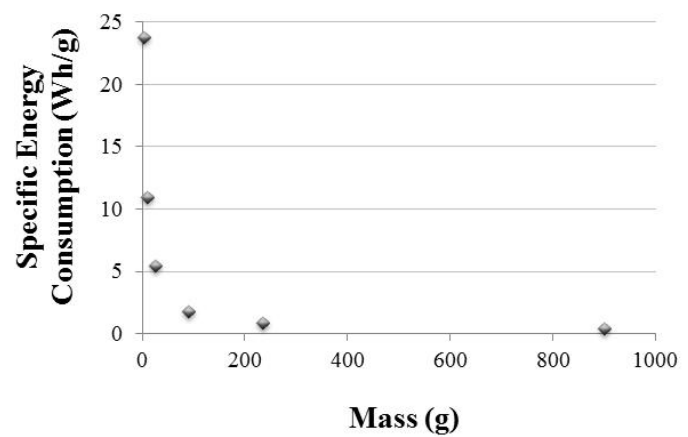

e)

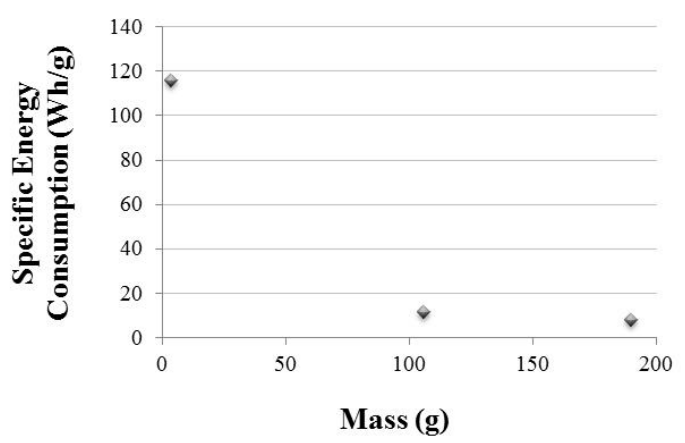

b)

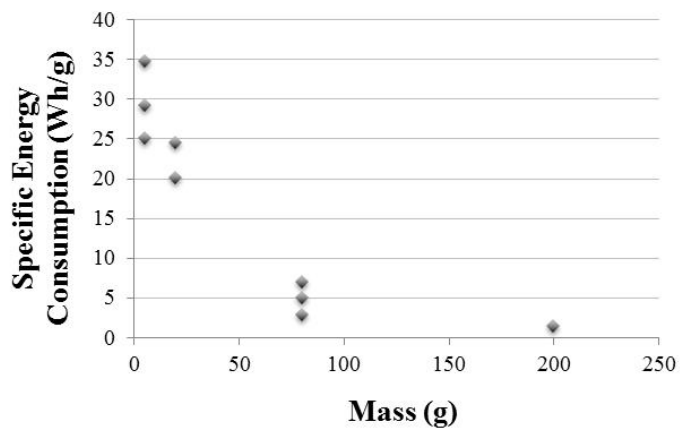

d)

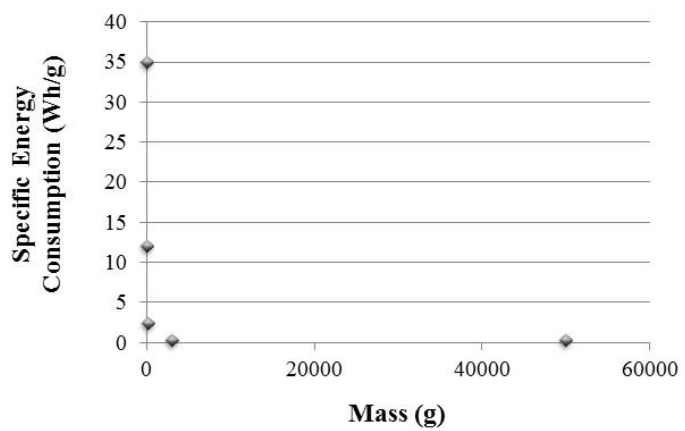

f)

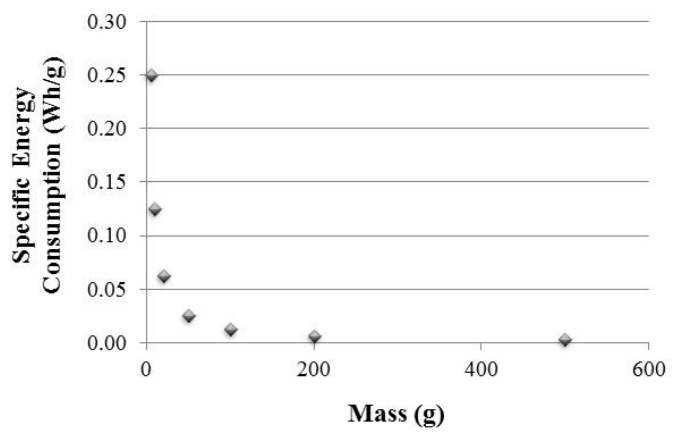

Figure 4. Variation of the specific energy consumption with mass for: (a) SiC heating;

(b) Torrefaction; (c) Water heating; (d) Xerogel synthesis; (e) High temperature heating of the carbon material (f) Coke grinding.

As can be seen, the energy consumption differs greatly in each process. In the case of the microwave-assisted grinding of metallurgical coke it ranges from $2.5 \cdot 10^{-3}$ to 0.25 
$\mathrm{W} \cdot \mathrm{h} / \mathrm{g}$, whereas in the case of the high temperature heating of carbonaceous materials it can reach values higher than $100 \mathrm{~W} \cdot \mathrm{h} / \mathrm{g}$. However, regardless of the type of process, the equipment used, the temperatures reached or the amount of energy needed, the variation in specific energy consumption follows the same trend in each case. When the experiments were performed using the lowest mass, the specific energy consumption was extremely high in comparison with the energy consumed when higher amounts of mass were used.

At first sight, this result might seem surprising. When conventional heating is used (ovens heated with electric resistances or fuel combustion) the walls and the cavity of the oven first need to be heated to supply the heat to the sample (heat transfer), resulting in excessive energy consumptions when low masses of sample are used (Fig. 5). However, when microwave heating is applied, the heat is generated from inside the material (energy conversion). Thus, the sample is directly heated, resulting in a much greater efficiency, since the energy losses due to the heating of the walls and the cavity of the oven are avoided or, at least, diminished (Fig. 5). For this reason, the power supplied to the sample can be adapted according to the amount of sample. In spite of this heating mechanism, the energy consumed per gram of mass of sample varies a lot depending on the amount of sample used. There is a sharp decrease in energy consumption from a few grams to about 50-100 g. From this point on, the decrease is more gradual. Eventually, when higher amounts of mass are used (on the scale of kilograms), the specific energy consumption shows practically constant values. The implication of this result is that, when a microwave system is not used at its maximum sample load capacity (which will depend on the design of its resonant cavity), there will be a significant waste of energy. Moreover, this inefficiency increases the further away 
the system operates from its maximum capacity. The importance of this cannot be underestimated since a microwave system designed to achieve optimum energy efficiency working far below maximum capacity will probably display a lower efficiency than a system of worse design operating closer to maximum capacity.

\section{Conventional}

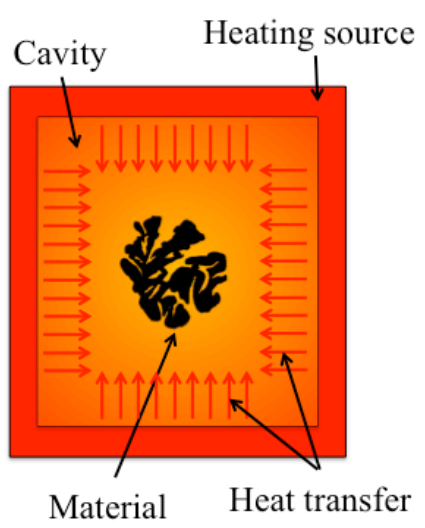

Microwave

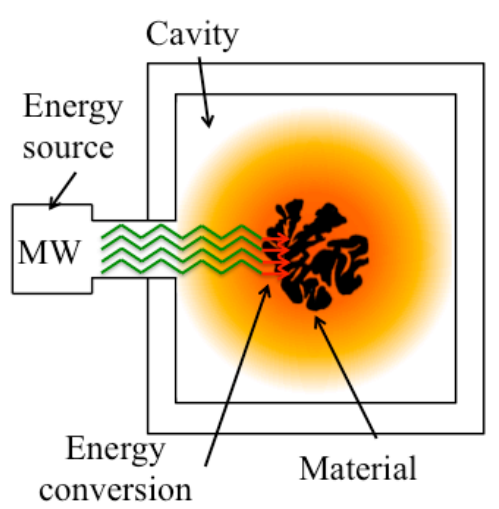

Figure 5. Conventional and microwave heating mechanisms.

To find a model that can be used to predict the energy consumption of microwavedriven processes, the energy consumptions of all the processes studied in this work were normalized. This has been done with the aim of set a proper comparison between the results previously published by other authors $[21,22]$ and the results obtained in the lab and published herein for the first time. To this end, 100\% of energy consumption was assigned to the energy consumed when the experiments were performed using the lowest amounts of sample $(\sim 5 \mathrm{~g})$. This normalization procedure to $100 \%$ allows the comparison between processes which specific energy consumption differs in several order of magnitude (from from $2.5 \cdot 10^{-3}$ to $0.25 \mathrm{~W} \cdot \mathrm{h} / \mathrm{g}$ in the microwave-assisted grinding of metallurgical coke to $100 \mathrm{~W} \cdot \mathrm{h} / \mathrm{g}$ in the high temperature heating of 
carbonaceous materials). The result of this normalization is depicted in Fig. 6. Table 3 shows the statistical fitting of the experimental data.

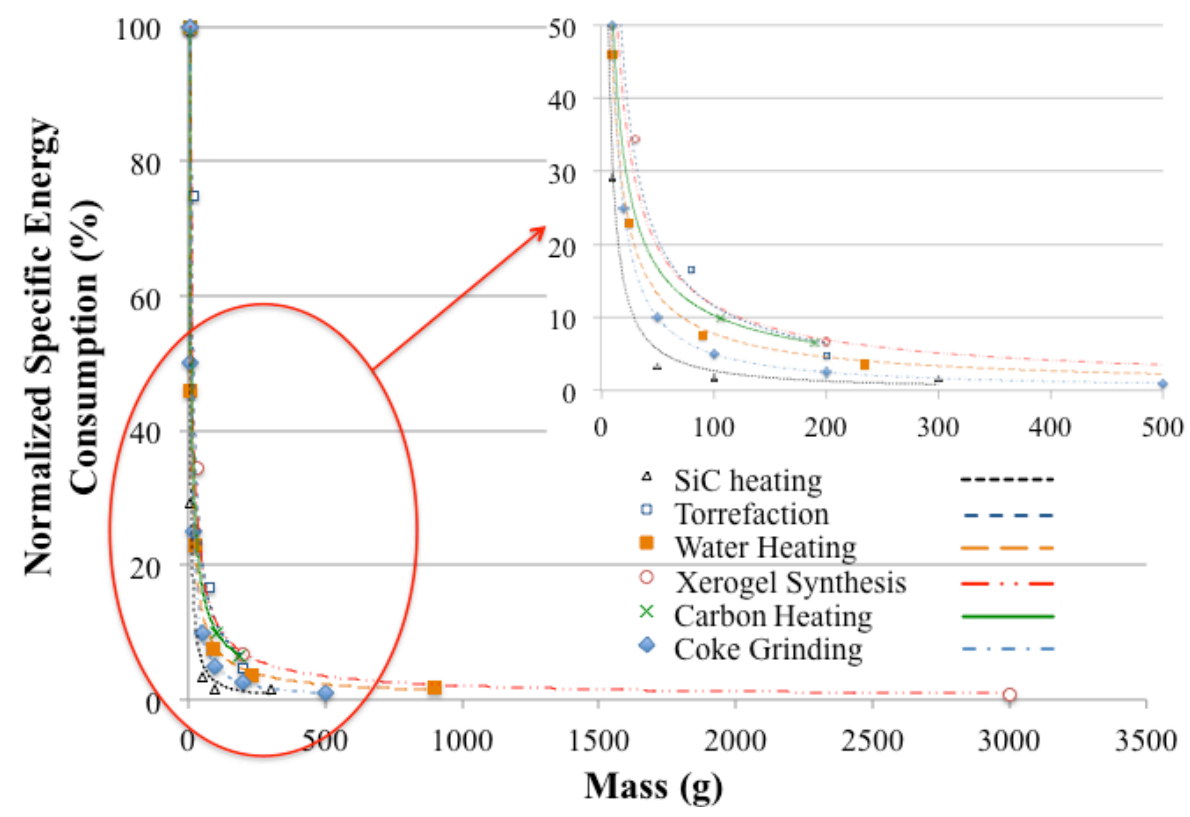

Figure 6. Normalization of the specific energy consumed in the microwave-assisted processes studied.

Table 3. Statistical correlations to the data obtained in the processes studied

\begin{tabular}{lccc}
\hline Process & Temperature $\left({ }^{\circ} \mathbf{C}\right)$ & Correlation $^{(\mathbf{a})}$ & $\mathbf{R}^{\mathbf{2}}$ \\
\hline SiC heating & 600 & $365 \cdot \mathrm{x}^{-1.1}$ & 0.91 \\
Torrefaction & 180 & $556 \cdot \mathrm{x}^{-0.8}$ & 0.91 \\
Water heating & 85 & $267 \cdot \mathrm{x}^{-0.8}$ & 0.99 \\
Xerogel synthesis & 80 & $373 \cdot \mathrm{x}^{-0.8}$ & 0.99 \\
High temperature carbon & 900 & $266 \cdot \mathrm{x}^{-0.7}$ & 0.99 \\
heating & - & $500 \cdot \mathrm{x}^{-1.0}$ & 0.99 \\
Coke grinding & - &
\end{tabular}

(a) The " $x$ " used in the correlations represents the weight of the sample

As can be seen, regardless of the process and the equipment used, the results of the normalization are very similar. Particularly remarkable is that even when using 
extremely different microwave devices, the trends of the energy consumption follow almost the same pattern. In all cases, when the process is scaled-up from $5 \mathrm{~g}$ to $100 \mathrm{~g}$, there is a decrease in specific energy consumption of about $90-95 \%$. Similar conclusions, applied only to the case of microwave-assisted organic synthesis, were drawn in a study by Moseley and Kappe [13]. This is a result of some considerable importance seeing that approximately half of the papers published from which highly influential conclusions about energy consumption have been drawn were works that used less than $25 \mathrm{~g}$ of sample (Fig .1), which would give rise to extremely overestimated energy values. However, on the basis of the data obtained in the present study at lab-scale, these results can be corrected to draw more accurate conclusions. Moreover, the results provided in this work may well help to predict the energy consumptions in large-scale microwave-heated processes. To validate this procedure as a means of predicting the energy consumption of a large-scale process using data obtained at lab-scale, data provided by the carbon gel company Xerolutions, S.L. were employed. The microwave used at large-scale has a resonant cavity capable of housing $40 \mathrm{~kg}$ of precursor solution. This equipment is composed of a microwave magnetron that operates at $2450 \mathrm{MHz}$. The experimental data from this process show that during the time needed for the gelation and curing to take place, the specific energy consumption was $0.29 \mathrm{~W} \cdot \mathrm{h} / \mathrm{g}$. If the specific energy consumption of the large-scale process is compared with the lab-scale process in which $3 \mathrm{~kg}$ of precursor solution were used (i.e. $0.31 \mathrm{~W} \cdot \mathrm{h} / \mathrm{g}$ ), it can be inferred that the specific energy consumption decreases. These results confirm that at a larger scale the specific energy consumption will continue to decline, although at a more moderate rate, until it becomes almost constant. This validates the procedure proposed for application to real industrial data. 
However, energy consumption is also closely related to another important parameter: energy efficiency, which could also vary with the scale. The energy efficiency of heating the water was determined, and found to follow the inverse trend to that of energy consumption (Fig. 7). As the amount of sample increases, the energy efficiency also increases, approaching an asymptotic value close to $30 \%$. The low efficiency at lower amount of water is due to the fact that higher reflected power is attained and even heating losses by convection from water to the surrounding air are more favored because of the higher surface area, leading to a higher rate of heat losses compared to the heat generation rate. These results agree with similar results obtained by other researchers in the unimode microwave heating of demineralized water [16], reinforcing the idea that, with independence of the mode of heating and the configuration of the equipment used, the microwave heating present the same general trend in terms of the variation of the energy efficiency with the increase of the scale. Although this might seem a low value, it has to be considered that the device used was a lab-equipment not specifically designed for maximizing energy efficiency. A more appropriate geometry, field distribution or isolation would improve this value. In the other cases studied this task is not as straightforward for various reasons such as the complex chain of reactions involved in the gelation and curing of $\mathrm{R} / \mathrm{F}$ xerogels or the geometry of the reactor used in the high temperature heating of carbon materials. In the case of the torrefaction of wheat straw, the authors did not study the change in efficiency with the scaling-up, although they arrived at the conclusion that the efficiency of this process was 1.5 times higher than that of the process carried out by conventional heating. This result points to the potentially better energy performance of microwave heating over conventional heating in certain processes. 


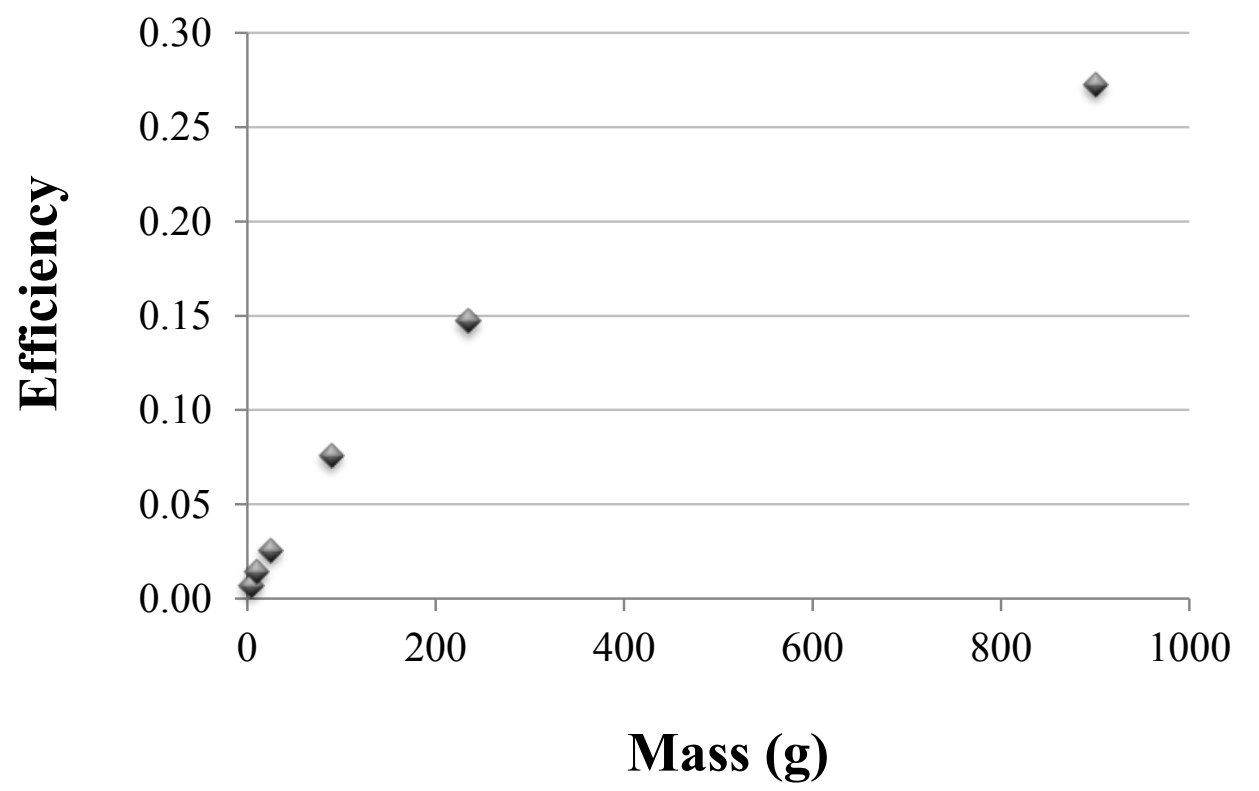

Figure 7. Energy efficiency in the microwave heating of water.

\section{Conclusions}

The energy efficiency of microwave heating technology depends to a large extent on the scale of the process. It was found that, regardless of the process, the equipment used, and the operating conditions, the variation in energy consumption (i.e., absorbed and reflected energy considering heating losses) follows the same trend depending on the amount of sample used. When the amount of sample employed is increased from 5 to $100 \mathrm{~g}$, the specific energy consumption decreases by $90-95 \%$. After this point, although the decrease in energy consumption continues, the reduction is not as pronounced. Above $200 \mathrm{~g}$, the specific energy consumption remains practically constant. These results underline the importance of studying the energy efficiency of a microwavedriven process using high amounts of sample (about $200 \mathrm{~g}$ or more). From the trends observed in this work at laboratory scale the energy expenditure of these processes can be predicted when applied on a larger scale. 


\section{Acknowledgements}

The research leading to these results has received funding from the European Union Seventh Framework Programme (FP7/2007-2013) under grant agreement $n^{\circ} 311815$ (SYNPOL project). D. B. and N.R.R. are also grateful to FICYT of the Government of Principado de Asturias (Spain) and the Ministry of Economy and Competitiveness of Spain (under Project MAT2011-23733), respectively, for their predoctoral research grants. The help of Xerolutions S.L. in providing experimental data is also acknowledged.

\section{References}

[1] J.A. Menéndez, A. Arenillas, B. Fidalgo, Y. Fernández, L. Zubizarreta, E.G. Calvo, J.M. Bermúdez, Microwave heating processes involving carbon materials, Fuel Process. Technol. 91 (2010) 1-8.

[2] C. Oliver Kappe, Microwave dielectric heating in synthetic organic chemistry, Chem. Soc. Rev. 37 (2008) 1127-1139.

[3] K.E. Haque, Microwave energy for mineral treatment processes - A brief review, Int. J. Miner. Process. 57 (1999) 1-24.

[4] Y. Fernández, J.A. Menéndez, Influence of feed characteristics on the microwave-assisted pyrolysis used to produce syngas from biomass wastes, J. Anal. Appl. Pyrolysis 91 (2011) 316-322.

[5] D. Bogdal, P. Penczek, J. Pielichowski, A. Prociak, Microwave assisted synthesis, crosslinking, and processing of polymeric materials, Adv. Polym. Sci. 163 (2003) 193-263.

[6] G.A. Tompsett, W.C. Conner, K.S. Yngvesson, Microwave synthesis of nanoporous materials, ChemPhysChem 7 (2006) 296-319.

[7] Y. Zhao, J.M. Gao, Y. Yue, B. Peng, Z.Q. Que, M. Guo, M. Zhang, Extraction and separation of nickel and cobalt from saprolite laterite ore by microwave-assisted hydrothermal leaching and chemical deposition, Int. J. Min. Met. Mater. 20 (2013) 612-619.

[8] X. Zhang, D.O. Hayward, Applications of microwave dielectric heating in environment-related heterogeneous gas-phase catalytic systems, Inorg. Chim. Acta 359 (2006) 3421-3433.

[9] P. Lidström, J. Tierney, B. Wathey, J. Westman, Microwave assisted organic synthesis - A review, Tetrahedron 57 (2001) 9225-9283. 
[10] D.A. Jones, T.P. Lelyveld, S.D. Mavrofidis, S.W. Kingman, N.J. Miles, Microwave heating applications in environmental engineering - A review, Resour. Conserv. Recy. 34 (2002) 75-90.

[11] G. Cravotto, L. Boffa, S. Mantegna, P. Perego, M. Avogadro, P. Cintas, Improved extraction of vegetable oils under high-intensity ultrasound and/or microwaves, Ultrason. Sonochem. 15 (2008) 898-902.

[12] F. Motasemi, M.T. Afzal, A review on the microwave-assisted pyrolysis technique, Renew. Sust. Energ. Rev. 28 (2013) 317-330.

[13] J.D. Moseley, C.O. Kappe, A critical assessment of the greenness and energy efficiency of microwave-assisted organic synthesis, Green Chem. 13 (2011) 794806.

[14] C. Yin, Microwave-assisted pyrolysis of biomass for liquid biofuels production, Bioresour. Technol. 120 (2012) 273-284.

[15] V.K. Tyagi, S.L. Lo, Microwave irradiation: A sustainable way for sludge treatment and resource recovery, Renew. Sust. Energ. Rev. 18 (2013) 288-305.

[16] R. Hoogenboom, T.F.A. Wilms, T. Erdmenger, U.S. Schubert, Hoogenboom, Aust. J. Chem. 62 (2009) 236-243.

[17] H. Cho, F. Török, B. Török, Energy efficiency of heterogeneous catalytic microwave-assisted organic reactions, Green Chem. 16 (2014) 3623-3634.

[18] M. Nüchter, B. Ondruschka, W. Bonrath, A. Gum, Microwave assisted synthesis - A critical technology overview, Green Chem. 6 (2004) 128-141.

[19] R. Morschhäuser, M. Krull, C. Kayser, C. Boberski, R. Bierbaum, P.A. Püschner, T.N. Glasnov, C.O. Kappe, Microwave-assisted continuous flow synthesis on industrial scale, Green Process. Synth. 1 (2012) 281-290.

[20] G.S.J. Sturm, M.D. Verweij, T.v. Gerven, A.I. Stankiewicz, G.D. Stefanidis, On the parametric sensitivity of heat generation by resonant microwave fields in process fluids, International Journal of Heat and Mass Transfer 57 (2013) 375-388.

[21] V.L. Budarin, P.S. Shuttleworth, J.R. Dodson, A.J. Hunt, B. Lanigan, R. Marriott, K.J. Milkowski, A.J. Wilson, S.W. Breeden, J. Fan, E.H.K. Sin, J.H. Clark, Use of green chemical technologies in an integrated biorefinery, Energ. Environ. Sci. 4 (2011) 471-479.

[22] P. Veronesi, Electromagnetic simulations in MW and RF processing, AMPERE Short CourseNottingham, UK, 2013.

[23] E.J. Juárez-Pérez, E.G. Calvo, A. Arenillas, J.A. Menéndez, Precise determination of the point of sol-gel transition in carbon gel synthesis using a microwave heating method, Carbon 48 (2010) 3305-3308.

[24] E.G. Calvo, E.J. Juárez-Pérez, J.A. Menéndez, A. Arenillas, Fast microwaveassisted synthesis of tailored mesoporous carbon xerogels, J. Colloid Interf. Sci. 357 (2011) 541-547.

[25] N. Rey-Raap, J. Angel Menéndez, A. Arenillas, RF xerogels with tailored porosity over the entire nanoscale, Micropor. Mesopor. Mat. 195 (2014) 266-275.

[26] X.-Y. Li, J. Yan, H. Yang, T. Peng, Q.-C. Yang, Study on processing technology for microwave pyrolysis of municipal solid waste, International Conference on Materials for Renewable Energy \& Environment (ICMREE), 2011, pp. 336-340.

[27] S. Kaiqi, W. Tao, Y. Jiefeng, Z. Haitao, E. Lester, Microwave enhanced pyrolysis of gumwood, International Conference on Materials for Renewable Energy and Environment (ICMREE), 2013, pp. 223-227.

[28] E. Ruisánchez, A. Arenillas, E.J. Juárez-Pérez, J.A. Menéndez, Pulses of microwave radiation to improve coke grindability, Fuel 102 (2012) 65-71. 
Final version published in Chemical Engineering and Processing: Process Intensification, 2015, 95, 1-8 